\title{
The Multiproblem Family Presents in a Children's Outpatient Psychiatric Clinic
}

\author{
Matthew Schiff, MD \\ Neil Kalter, PhD \\ University of Michigan Medical Center
}

ABSTRACT: This study focuses on children from multiproblem families when they appear at an outpatient psychiatric clinic for children. The sample consisted of the first 50 children and their families referred to a large children's outpatient psychiatric facility early in 1974. A multiproblem family was defined in terms of the number of helping agencies and/or professionals contacted by family members within the 3-year period prior to the current psychiatric evaluation and by the number of households in which the designated child patient had lived. Eighteen percent of the 50 cases met the criteria established for a multiproblem family. These indicators successfully differentiated multiproblem from nonmultiproblem families along a number of socioeconomic, demographic, family health, and family stability dimensions. Special difficulties encountered in psychiatrically evaluating children of such multiproblem families are presented, and ways of dealing with them are discussed.

The term "multiproblem family" was popularized in the mid-1950s following a significant study of these families in Saint Paul, Minnesota [1]. Descriptions and definitions of multiproblem families have not undergone significant alteration since the term was introduced into the literature. The Minnesota study described these families as

extremely troublesome to the community. By reason of child neglect, crime, dependence on relief, truancy, delinquency, problem drinking, and many other deviant kinds of behavior, they represent the threat of financial burden to the community. Second, they are troubled people, unhappy and suffering, whose feelings of self-worth are low. In many subtle (and unsubtle) ways they have been told they are failures as family providers, as parents, as neighbors, etc., and have heard this so often that they have come

Dr. Schiff is a Fellow in Child and Adolescent Psychiatry, Children's Psychiatric Hospital, University of Michigan Medical Center. Reprint queries should be directed to Dr. Kalter at Children's Psychiatric Hospital, University of Michigan Medical Center, Ann Arbor, Michigan 48104. 
to believe it themselves. It is not surprising that they are defensive and mistrustful, seeing society in all its parts, including social workers, as a threat.

They have been aptly described by Polanski et al. [2] in their book about West Appalachian multiproblem families as people who breathe apathy and futility.

The following characteristics are seen as most important in defining the nature of multiproblem families $[1,3,4]$ :

1. Multiplicity of problems: There should be two or more recent problems involved in the case.

2. Chronicity of need: There is a history of consistent and recurrent multiple difficulties producing family and individual disorganization.

3. Resistance to treatment: This may range from an inability to ask for or use help appropriately to rejection of help offered.

4. Handicapping attitudes: This includes lack of understanding of the meaning and value of formal education or modern medical care [3].

In referring to the various attempts to intervene with multiproblem families in the area of mental and physical health care and school and job counseling, Cohen and Bernard [3] note:

In these very families that need it most, agency services tend to be either rejected, or if begun, discontinued. This resistance to treatment-or in some instances, outright rejection of treatment-may take the form of not making use of suggested casework services, of failing to act on early symptoms of cancer, diabetes or tuberculosis, of breaking probation, of school drop-outs, of failure to follow up on suggested opportunities for employment. Since traditional concepts of agency service are based on "client initiative," conventional casework approaches either do not reach these people or fail to "take."

An examination of several studies of multiproblem families reveals that a large number of children in these families are at risk psychiatrically due to disturbing rates of interpersonal and emotional difficulties among parents and/or parent surrogates, and a high incidence of disrupted, broken homes. These families tend to be isolated from their communities and mental health workers. Their child care practices, economic situations, household practices, and physical and mental health are generally inadequate $[1,4,5]$. Many studies agree that these families drain up to $36 \%$ of the resources spent and given to correctional, health, mental health, and public relief services, despite the fact that they represented only approximately $5 \%$ of the total families in a community $[1,5,6]$.

Multiproblem families differ with respect to national norms for 
families along many dimensions. In the Saint Paul study the average size of the family was 7.4 members compared to 5.5 members in the general population. Approximately $50 \%$ of their families were oneparent families. Over $30 \%$ of multiproblem families contained a woman who married at under 18 years of age. The national average in the late ' 50 s was $18 \%$. Approximately $70 \%$ of these families received significant financial aid [1]. The New York Youth Board families were similar to those studied in Minnesota with respect to use of financial welfare aid, court systems, and protective services. In both samples over $75 \%$ of both sets of these families were involved with these agencies $[1,4]$.

A further elaboration of the types of significant parental difficulty was done in the New York study. A total of 236 parents were studied: (a) 54 had physical disease; (b) 26 had diagnosed mental deficiency or disease; (c) 34 had severe drug abuse problems; (d) 36 had physically abused or neglected their children; and (e) 64 were out of the home because of death or desertion. These figures are described as minimal estimates [4]. Howell's [7] study of hard-core families in England revealed an incidence of significant emotional pathology in $98 \%$ of these families as compared to $30 \%$ in the general population. He defined "significant" as multiple symptomatology with only a fair chance of amelioration even with long-term psychotherapy.

Generally, many factors seemed to interrelate and compound one another in a negative fashion. The poorer the family solidarity, the greater the chance of individual socially or mentally disordered behavior. All of these factors negatively influenced money management and the state of individual and family health. These families seemed to pick different agencies and present in "different" crises. These crises seem predictable. They can all be understood through one's knowledge and understanding of the multiproblem family [1].

While research on multiproblem families has carefully described the range and depth of difficulties confronting these families, there is little literature concerning psychiatric aspects of the children of multiproblem families. To examine this issue the first 50 cases referred for evaluation at a large outpatient children's psychiatric facility were studied.

\section{Procedure}

A psychiatric evaluation at this clinic consisted of an average of two interviews with the designated child patient, two appointments with the child's parents or guardians, and an interpretive, feedback interview with the parents/guardians.

Data on these 50 cases included general demographic and socioeconomic in- 
formation as well as material elicited in the psychiatric interviews. The former consisted of parents' or guardians' age, race, religion, education, occupation, and income, and the child's age, sex, and grade in school. Interview data included the number of caretakers and households involved in the child's life, the overall mobility and intactness of the family, contacts that all known members of the immediate family had with helping agencies and/or professionals since January 1971 , and the data on intrapsychic and family assessment of conflicts and problems.

\section{Results}

The first step in analyzing these data involved developing an empirical definition of the multiproblem family. We thought that the number of helping agencies and/or professionals contacted by family members in the most recent 3 -year period would reflect the chronicity and multiplicity of problems that other investigators have noted as a major characteristic of multiproblem families. An inspection of the distribution of this variable in our sample showed that contact with six or more agencies and/or helping professionals provided a natural cutting point. In addition, an index of lack of family stability, another important aspect of the multiproblem family condition, was sought. Thus it was decided that if the child patient had lived in two or more households over the 3-year period prior to the evaluation, it would be an indication of family instability. Both of these criteria were applied to the 50 families, and 9 families met both criteria. The median number of helping agencies and/or professionals contacted by the multiproblem families was seven; for the nonmultiproblem families, three. The median number of households in which the multiproblem child patients had lived was four; the corresponding figure for the nonmultiproblem children was one. The fact that as many as $18 \%$ of the sample came under our operational definition of a multiproblem family was in itself an interesting and surprising datum.

The next step was to compare the multiproblem (MP) and nonmultiproblem (NMP) families with respect to five sets of variables: demographic, socioeconomic, family health, family stability, and evaluation-related variables. In each instance the dependent variable was dichotomized, yielding a two-by-two contingency table (i.e., MP vs. NMP and the two elements of the dichotomized dependent variable). A Fisher exact test was performed for each table to determine if differences between the MP and NMP families were statistically significant. Table 1 summarizes these analyses.

An inspection of Table 1 shows that MP families differed significantly from NMP families on nearly all the variables examined. The exceptions were race, sex, and age (teen vs. preteen) of the child pa- 
TABLE 1

Comparison of Multiproblem and Non-Multiproblem Families

on Demographic, Socioeconomic, Family Health,

Family Stability, and Evaluation Variables

\begin{tabular}{|c|c|c|c|}
\hline \multirow[b]{2}{*}{ Demographic } & \multicolumn{2}{|c|}{$\begin{array}{c}\text { Percent of } \\
\text { Families among } \\
\text { MP vs. NMP }\end{array}$} & \multirow[t]{2}{*}{ Significance } \\
\hline & & & \\
\hline Age of child patient (13-17 years old) & 44 & 41 & N.S. \\
\hline Sex of child patient (male) & 67 & 56 & N.S. \\
\hline Race (non-white) & 33 & 10 & N.S. \\
\hline Number of siblings and/or stepsiblings $(>2)$ & 56 & 15 & $*$ \\
\hline \multicolumn{4}{|l|}{ Socioeconomic } \\
\hline Mother's education $(<12 \text { years })^{1}$ & 100 & 27 & $* *$ \\
\hline Father's education $(<12 \text { years })^{2}$ & 100 & 23 & $* *$ \\
\hline Receiving ADC (yes) & 89 & 2 & $* *$ \\
\hline \multicolumn{4}{|l|}{ Family Health } \\
\hline \multicolumn{4}{|l|}{ One or both parents hospitalized within the } \\
\hline last three years & 44 & 2 & ** \\
\hline \multicolumn{4}{|l|}{ Child patient's siblings and/or stepsiblings } \\
\hline with clear psychiatric problems ${ }^{3}$ & 88 & 11 & $* *$ \\
\hline \multicolumn{4}{|l|}{ Family Stability } \\
\hline Number of moves $(>2)$ & 89 & 12 & $* *$ \\
\hline Not currently living with either biological parent & 78 & 5 & $* *$ \\
\hline \multicolumn{4}{|l|}{ Evaluation } \\
\hline Referral by DSS or court & 67 & 2 & $* *$ \\
\hline Length of evaluation ( $>6$ weeks) & 89 & 37 & $* *$ \\
\hline
\end{tabular}

$*=p<.05$

$* *=p<.01$

${ }^{1}$ Based on 6 multiproblem families and 38 non-multiproblem families.

${ }^{2}$ Based on 5 multiproblem families and 37 non-multiproblem families.

${ }^{3}$ Based on 8 multiproblem families and 36 non-multiproblem families.

tient. There does not seem to be any relationship between these demographic measures and coming from an MP family.

A picture of the MP families emerges from the analysis of the remaining quantitative data. Contrasted with the NMP group, MP families were larger, poorer, less well educated, and less healthy. These differences were striking. Eighty-nine percent of the MP families were receiving Aid to Dependent Children (ADC), and none contained a parent who had completed a high school education. Fully $44 \%$ of the MP families had a parent who had been hospitalized for a psychiatric and/or medical problem within the last 3 years. Among the eight MP families where the designated child patient had a sibling and/or step- 
sibling, seven contained another child with clear-cut psychiatric problems. Thus, the two relatively straightforward criteria used to identify MP families seemed to locate these families efficiently in our sample.

Differences between the two family groups with respect to the evaluation process were also in evidence. Sixty-seven percent of the MP families as opposed to only $2 \%$ of the NMP group had the target child patient referred by the courts or the Department of Social Services rather than the more common sources such as school, family physician, or the child's parents or guardians. And evaluations took considerably longer to complete for children of MP families. Eightynine percent of the MP families had evaluations that extended beyond 6 weeks, while only $37 \%$ of the evaluations of NMP families took this long. Many MP families bring their children for an outpatient psychiatric evaluation when under some pressure from a social agency to do so. And the evaluation process is unusually prolonged often due to missed appointments which need to be rescheduled and the complexity of the task of collecting relevant information from a large number of community agencies and professionals.

In addition to the quantitative differences between MP and NMP families, there were clinical dissimilarities as well. Among our 41 NMP families, two types of problems were prevalent. The first was an essentially neurotic difficulty occurring within an intact family. These included instances of enuresis, phobias, learning inhibitions, behavioral problems, and so forth. A second pattern of difficulties consisted of acute developmental or environmental crisis cases. Included in this group were adolescent adjustment problems (e.g., school truancy, runaway behavior, and drug taking), reactions to birth of a sibling, and custody cases. In contrast to these kinds of psychiatric and behavioral problems, the children of MP families seemed to present with smoldering, chronic difficulties occurring in a family setting that lacked definition and cohesion. The child's problem, itself, rarely could be clearly defined. An atmosphere of chaos and uncertainty pervaded the material. And evaluators often felt confused and helpless in the face of long and tortuous histories of family difficulties and multiple social agency contacts.

\section{Case Studies}

\section{Case 1}

The case of John J., a 12-year-old boy, had an unsatisfactory resolution. John was referred by the Department of Social Services for evaluation and disposition. 
He had been in five different residences in the 3 years prior to his evaluation, including placements in a group home, a juvenile boys' home, and a children's psychiatric hospital. In between placements he had stays of various lengths with his biological mother and stepfather, and his biological father. His six siblings in his two families were just as dispersed and fragmented in their living arrangements as was John. Previous evaluations noted marked disturbed and antisocial behavior. The list of difficulties included enuresis, fire setting, fighting, stealing, poor school adjustment with a normal IQ, and physical abuse of his siblings and biological mother.

John was taken to another state precipitously, but with the state's permission, by his biological father; this solved the disposition problems. It obviously did not touch on the dilemma of beneficial management for John, his siblings, or his sets of parents. This evaluation lasted 8 weeks and was mostly focused on liaison with social agencies that had had contact with this family in order to gather pertinent historical information. Neither John nor his parents were ever seen as part of the evaluation.

\section{Case 2}

Lucretia G. is an $8 \frac{1}{2}$-year-old girl whose difficult but successful evaluation took 21 weeks to complete. Much of this time was spent compiling data and mobilizing services 70 miles away from the clinic. This task involved liaison work with the seven agencies that had had contact with the G.'s over the last 3 years. These agencies included Aid to Dependent Children, Department of Social Services, Protective Services, three medical hospitals, and many helping resource people at Lucretia's school.

Lucretia was described by various medical, helping, and school personnel as sleepy, lethargic, hyperactive, retarded, abused, and just plain confused. People who attempted to diagnose her difficulties further felt frustrated and overwhelmed as they uncovered the existence of two homes (the mother's and grandmother's), an absent and previously abusing father, and a mother and grandmother who seemed to shift their feelings toward and responsibility for Lucretia. In addition, a difficult diagnostic assessment was needed that called for pediatric and neurological review and psychological testing.

The evaluation proceeded with the patient being brought in on the wrong hour of the wrong day. When she finally was seen, Lucretia had difficulty leaving the evaluator's office. In all three interview sessions she left drawings for the evaluator. These pictures and specimens of her writing indicated the presence of some problem in perceptual-motor integration. It was already known that she was myopic and had significant nerve hearing loss in her left ear. Difficulties in the use of language were also present. Her enunciation of words made it difficult to understand her vocabulary and its syntax. She also had difficulty hearing and particularly integrating instructions. When Lucretia wanted to learn to use the office dictaphone, verbal and nonverbal instructions had to be repeated many times before she learned to master this activity. But, despite obvious difficulties in perception and particularly integration, she could clearly communicate a sense of her psychological world. Her object hunger and her wish for people to stay involved with and not abandon her were poignantly obvious. She made it clear despite her somewhat damaged equipment that she wanted to and would communicate with people if she had the chance. She would only get angry and flail out at 
people when she felt that they were not understanding her. This anger and oppositional behavior would provoke negative reactions from peers and adults, thus sustaining her feelings of being a damaged, abused, and worthless girl.

Lucretia's family circumstances, past and present, contain chaotic, frightening events. Mrs. G., a blustery woman, tried to lead with a show of force. She would yell and chide the secretaries and the evaluator about all the things the clinic had done wrong. Underneath this exterior, there was a very passive, dependent, frightened, ill (diagnosed tuberculosis) woman who had herself been abandoned by her father as a child. She still required her mother to drive on almost all trips no matter how brief. Often she would leave responsibility for the supervision of her children to her mother. This was gladly accepted; the grandmother preferred to keep her daughter childlike and helpless. In fact it took both "parents" to give any semblance of a developmental history for Lucretia. It was filled with moves, unfortunate surprises, and unexpected happenings. Lucretia had to face at $2^{1 / 2}$ her father's hospitalization for alcoholism manifested by destructive and abusive behavior toward his children and family, at 3 her mother's hospitalization for tuberculosis, at 4 a fire in their house in a southern state while they were vacationing in Chicago, and, at various ages, four moves.

It was decided that the interpretive interview with the school, its social worker, and its learning disability team, and the interview with the mother and grandmother, would be held in the small town where the referral originated. Together with a number of school specialists, a program for this perceptually and emotionally damaged youngster was established. Lucretia is now learning in her resource room at school with a minimum of behavioral difficulties. The epilogue to this 21-week adventure was a call to the evaluator some 6 months later about a second child in this family of three siblings who was having sudden problems with sexual identity. The G.'s seemed more trusting and more willing to cooperate in helping this second child than they initially had been in Lucretia's case. The integrated, active effort of several helping professionals seemed to leave its mark upon the G.'s.

\section{Discussion}

The first step in developing practices for the useful psychiatric evaluation of children from multiproblem families is to recognize such children when they present at a clinic or community agency. Without the realization that one is dealing with a child from a multiproblem family and without the concept of such a family, the evaluator can often feel inundated by the amount of time, energy, and patience that is required in compiling relevant historical data and developing a constructive diagnostic assessment of the current psychological and situational difficulties. If one proceeds on a case-by-case basis without this perspective, feelings of frustration and helplessness soon beset the evaluator.

In our sample, a constellation of characteristics was descriptive of MP families. The family's having had extensive (six or more) contacts with helping agencies and/or professionals in the most recent 3-year 
period and the child patient's having lived in two or more households proved to be relatively straightforward indicators of a multiproblem family. These "signs" were associated with a host of socioeconomic, family health, and family stability characteristics. Demographic variables, however, such as age, sex, and race of the child patient, were not aspects that differentiated children of MP from those of NMP families.

While parents of MP families were consistently poorer and less well educated than NMP parents, low socioeconomic status is not to be equated with being a multiproblem family. Rather, it seems that family instability and long-standing physical and/or psychiatric problems of family members are the key features of a multiproblem family. In the sample studied, all MP families were of low socioeconomic status, but it seems that this compounds the problems MP families face rather than causing them $[2,7]$.

Once a particular family is recognized as being a multiproblem family, the helping professional should be prepared for an evaluation that is longer than usual and that involves contacting numerous agencies and professionals. Often the evaluator is confronted by crises in at least two areas, within the families and among the helping agencies. With respect to the latter, the agencies are frequently unaware of one another's involvements. Thus, an important early step in the evaluation process is to collate relevant data from multiple sources. When the integrated information is communicated to each of the agencies, a recognition of the extent and nature of the difficulties serves to decrease the global sense of futility and paralysis separately and yet mutually experienced by those who have been in contact with the multiproblem family. A concerted plan for intervention then can be devised through a cooperating team of professionals drawn from the several agencies involved $[6,8]$. Such an effort recognizes the need for effective intervention to be multifaceted and drawn from several resources when helping a multiproblem family. In the case of Lucretia G., intervention included coordinating the efforts of several educational specialists as well as attention to Mrs. G.'s medical problems. The intervention plan rested on knowledge of the psychological, cognitive, and neurological aspects of Lucretia's functioning and on mother's past medical history. Thus a number of helping agencies and professionals were involved including school personnel, a pediatric neurological unit at a hospital, and medical personnel who had previous contact with the G.'s and especially with Lucretia.

Concurrent with the coordination among the several agencies and helping professionals involved, the family and child should be seen as 
quickly as possible. Delay of even a week can lend support to the family's feeling that agencies are basically unresponse to their needs and increase their resistance to being helped. Further, such families will often act precipitously, thus aborting the evaluation process as in the case of John J. Home visits or meeting the family elsewhere in its community can be particularly effective in demonstrating a commitment to be helpful to the family and where speed in seeing the family is crucial $[2,9]$.

We have found it helpful in evaluating multiproblem families to emphasize to the family the potential strengths the child has and the specific steps that can be undertaken to aid the child and other family members. Here one's role as a coordinator of multiple services involving several agencies or institutions is important. What is stressed is clear-cut action that will take place in the near future. Multiproblem families often cannot afford the luxury, nor do they usually have the inclination, to observe themselves at length in a psychologically minded fashion with no tangible action planned. And in most instances they are correct in feeling that such highly visible actions are what the situation requires.

Multiproblem families present special difficulties in the psychiatric evaluation of children. And our sample findings suggest that children of these families may be appearing in substantial numbers at large outpatient psychiatric facilities. The recognition of these families and the problems they face lends a perspective to the evaluation of these children that is in itself useful to the mental health professional. An emphasis on coordinating information from and resources of the numerous agencies involved with the multiproblem family seems essential in arriving at a constructive assessment and plan for intervention. Quickly seeing the family and emphasizing readily observable actions to help with the difficulties they are experiencing can prove effective in delivering service.

\section{References}

1. Geismer LL: Families in trouble. Family Centered Project, Greater Saint Paul Community Chest and Councils, Inc, Saint Paul, Minnesota, 1958.

2. Polanski WA, Borgman RA, Desaix C: Roots of Futility. San Francisco, Jossey-Bass, 1972.

3. Cohen W, Bernard SE: The Prevention and Reduction of Dependency. Ann Arbor, Mich, Washtenaw County Department of Social Services, 1961.

4. New York City Youth Board: Reaching the Unreached. Monograph 1. New York, Author, 1952.

5. Brown GE: The Multiproblem Dilemma. Metuchen, NJ, Scarecrow Press, 1968. 
6. Curtis JL, Simon M, Boykin F, et al: Observations on 29 multiproblem families. Amer J Orthopsychiat 34:510-516, 1964.

7. Howell J: The psychopathogenesis of hard-core families. Amer J Psychiat 122:1159-1164, 1966.

8. Enzer NB, Stackhouse J: A child guidance clinic approach to the multiproblem family. Amer J Orthopsychiat 38:527-538, 1968.

9. Meyer C: Individualizing the multiproblem family. Soc Casework 44:267272,1963 . 